\title{
Prognostic significance of platelet- lymphocyte ratio in patients receiving first-line tyrosine kinase inhibitors for metastatic renal cell cancer
}

\author{
Tae Ju Park', Yang Hyun Cho ${ }^{1}$, Ho Seok Chung ${ }^{1}$, Eu Chang Hwang ${ }^{1^{*}} \mathbb{D}$, Sung-Hoon Jung ${ }^{2}$, Jun Eul Hwang ${ }^{2}$,
} Woo Kyun Bae ${ }^{2}$, Jin Woong Kim³ ${ }^{3}$, Suk Hee Heo ${ }^{3}$, Young Hoe Hur ${ }^{4}$, Seung II Jung ${ }^{1}$ and Dong Deuk Kwon ${ }^{1}$

\begin{abstract}
Background: The platelet-lymphocyte ratio (PLR) and neutrophil-lymphocyte ratio (NLR) have been reported as prognostic factors in various cancers, but their roles in metastatic renal cell cancer (mRCC) remain unclear. We investigated the significance of PLR and NLR, along with that of established prognostic factors, in mRCC patients receiving first-line tyrosine kinase inhibitors (TKI).

Methods: Data obtained from 63 mRCC patients who received first-line TKI between 2007 and 2013 were evaluated retrospectively. The association of PLR, NLR, and established prognostic factors with progression-free survival (PFS) and overall survival (OS) was analyzed using the Kaplan-Meier method. The influence of independent prognostic factors on survival was determined using multivariable Cox regression analysis.

Results: High NLR ( $>3.6)$ and PLR $(>150)$ were related to shorter PFS $(p=0.001)$ and OS $(p=0.001)$. The presence of brain metastases [hazard ratio (HR) 4.94,95\% Cl 1.75-13.9; $\mathrm{p}=0.002$ ] and high PLR (>150, HR 13.1, 95\% Cl 5.14-33.2; $p=0.001$ ) were independently associated with PFS, and Eastern Cooperative Oncology Group Performance status $\geq 2$ (HR 3.60, 95\% Cl 1.39-9.31; $p=0.008$ ), lymph node metastasis ( $H R 2.76,95 \% \mathrm{Cl} 1.11-6.86 ; p=0.029)$, brain metastasis (HR 9.39, 95\% Cl 2.74-32.1; $p=0.001$ ), and high PLR (>150, HR 16.1, 95\% Cl 4.41-58.4; $p=0.001$ ) with OS.
\end{abstract}

Conclusions: High PLR was associated with shorter survival of mRCC patients receiving first-line TKI. The PLR may be an effective independent prognostic factor in this setting.

Keywords: Platelet-lymphocyte ratio, Neutrophil-lymphocyte ratio, Neoplasm metastasis, Carcinoma, renal cell

\section{Background}

Renal cell carcinoma (RCC) is the most common type of kidney cancer in adults. It accounts for approximately $3 \%$ of adult malignancies and $90-95 \%$ of neoplasms arising from the kidney. Patients with RCC progress to a metastatic stage in approximately 33\% of cases (Gunduz et al. 2015). The management of patients with metastatic RCC (mRCC) is complicated by the lack of proven

\footnotetext{
*Correspondence: urohwang@gmail.com

1 Department of Urology, Chonnam National University Medical School,

42 Jebongro, Donggu, Gwangju 501-757, Republic of Korea

Full list of author information is available at the end of the article
}

effectiveness of accessible therapies. Recently, tyrosine kinase inhibitors (TKI) such as sunitinib, sorafenib, or pazopanib have become a common choice for first-line targeted treatment of mRCC (Noronha et al. 2016). Common metastatic sites include the lung, liver, bones, brain, and adrenal gland, while many case reports describe the capacity of RCC to metastasize almost anywhere in the body. More than one organ system is often affected by the metastatic process. Metastases may be found at the time of diagnosis or at any point after nephrectomy (Thyavihally et al. 2005). About $20-50 \%$ of patients will eventually develop a metastatic disease after nephrectomy. A shorter time interval between nephrectomy 
and the development of metastases is associated with a poor prognosis. Also, the presence of biological signs of inflammation, shorter time interval between diagnosing a renal tumor and developing metastases $(<1$ year), elevated neutrophil counts, liver metastases, bone metastases, patient performance status (PS), the number of metastatic sites, alkaline phosphatase and hemoglobin levels are predictive factors of survival outcome (Heng et al. 2009). The crucial role of microenvironment inflammation in the development and progression of malignancies by influencing the proliferation and survival of tumor cells, promoting angiogenesis and metastasis, and reducing responses to anti-cancer agents has been recognized (Gunduz et al. 2015; de Vivar Chevez et al. 2014). Recently, several biomarkers and hematological indices representative of systemic inflammatory responses, including the neutrophil-lymphocyte ratio (NLR), the platelet-lymphocyte ratio (PLR), and the combination of the C-reactive protein (CRP) and albumin known as the Glasgow prognostic score (GPS) were introduced as prognostic factors in various cancers. For example, the NLR and PLR have been suggested as prognostic indicators for lung, colorectal, breast, gastric and pancreatic cancer, as well as urinary cancers such as RCC, and urothelial carcinoma (Feng et al. 2014; Raungkaewmanee et al. 2012; Hu et al. 2015; Song et al. 2016; Nakano et al. 2014). Templeton et al. (2014a, b) investigated the prognostic role of NLR and PLR in solid tumors. In their meta-analyses, both high NLR and PLR were associated with adverse overall survival (OS). Moreover, the effect of high PLR on OS was greater for metastatic disease than for early stage disease (Templeton et al. 2014b). However, Keskin et al. (2014) showed that only preoperative high NLR was associated with mortality in renal cell carcinoma. Thus, the aim of this study was to investigate the relationship of NLR, PLR, and previously known prognostic factors with progression-free (PFS) and OS in patients with $\mathrm{mRCC}$.

\section{Methods \\ Patients}

The data of 63 patients who had received first-line TKI for mRCC between 2007 and 2013 were reviewed retrospectively. Patients with histologically confirmed mRCC (all clear cell histology) who had received first-line sunitinib or pazopanib according to the standardly approved schedule and dosage were eligible for this study. Sunitinib was administered at a dose of $50 \mathrm{mg}$ per day for 4 weeks, followed by a 2 -week rest. Pazopanib was administered at a dose of $800 \mathrm{mg}$ per day, continuously during 4 weeks. Both TKIs were prescribed strictly as monotherapy, in either standard everyday clinical practice or as a part of a clinical trial. Dose reduction was performed in a case of toxicity, according to standard recommendations for the two agents. Before treatment, the patient's age, sex, clinical symptoms, medical history, and performance status were evaluated by physicians. Blood samples were collected for serum chemistry and hematological testing. Chest, abdominal and pelvic computed tomography, and positron emission tomographycomputed tomography were also performed. Responses were evaluated every 8-12 weeks after the treatment initiation by chest and abdominopelvic computed tomography or by the same tests that were used to stage initial tumors. TKI therapy was given until objective disease progression per Response Criteria in Solid Tumors v. 1.1 criteria (Eisenhauer et al. 2009). PFS was defined as the period of time between the initial administration of a treatment and the first detection of tumor progression based on radiological criteria or death. OS was calculated from the start of treatment to the date of any cause of death.

\section{Assessment of Eastern Cooperative Oncology Group Performance status (ECOG-PS), NLR and PLR}

ECOG-PS was assessed at the time of diagnosis. Data on pretreatment blood cell counts were extracted in a retrospective fashion from the medical records. White blood cell and differential counts were assessed just prior to administration of TKIs. The NLR was defined as the absolute neutrophil count divided by the absolute lymphocyte count, and was categorized into two groups ( $\leq 3.6$ and $>3.6$ ). Similarly, PLR was defined as the absolute platelet count divided by the absolute lymphocyte count, and was also categorized into two groups $(\leq 150$ and $>150$ ). The cut-off values were evaluated using the receiver operating characteristic (ROC) curve.

\section{Statistical analysis}

Statistical analysis was conducted using IBM SPSS software package version 21.0 (Statistical Package for Social Sciences, IBM, Armonk, NY) and MedCalc software version 15 (MedCalc Software bvba, Ostend, Belgium). The PFS and OS were calculated using the Kaplan-Meier method. Multivariable analyses using the Cox regression proportional hazard model were performed to evaluate the prognostic significance of all parameters on PFS and OS. ROC curves were plotted to verify the accuracy of the obtained significance of NLR and PLR on overall survival prediction. A $p$ value $<0.05$ was considered as statistically significant.

\section{Results}

\section{Clinical characteristics}

The clinical characteristics of 63 patients who received first-line TKI for mRCC are summarized in Table 1. 
Table 1 Patient demographics

\begin{tabular}{|c|c|}
\hline Patient no., $\mathrm{n}$ & 63 \\
\hline Age, median (IQR) & $63.1(56.0-70.5)$ \\
\hline Median follow up, months (IQR) & $17.5(9.2-28.4)$ \\
\hline \multicolumn{2}{|l|}{ Sex, n (\%) } \\
\hline Male & $52(82.5)$ \\
\hline Female & $11(17.5)$ \\
\hline \multicolumn{2}{|l|}{ ECOG PS, n (\%) } \\
\hline $0-1$ & $36(57.1)$ \\
\hline$\geq 2$ & $27(42.9)$ \\
\hline \multicolumn{2}{|l|}{ Disease free interval, n (\%) } \\
\hline$<1$ year & $40(63.5)$ \\
\hline$\geq 1$ year & $23(36.5)$ \\
\hline \multicolumn{2}{|l|}{ Lung metastasis, n (\%) } \\
\hline Yes & $39(61.9)$ \\
\hline No & $24(38.1)$ \\
\hline \multicolumn{2}{|l|}{ Liver metastasis, n (\%) } \\
\hline Yes & $6(9.5)$ \\
\hline No & $57(90.5)$ \\
\hline \multicolumn{2}{|l|}{ Lymph node metastasis, n (\%) } \\
\hline Yes & $25(39.7)$ \\
\hline No & $38(60.3)$ \\
\hline \multicolumn{2}{|l|}{ Bone metastasis, n (\%) } \\
\hline Yes & $19(30.2)$ \\
\hline No & $44(69.8)$ \\
\hline \multicolumn{2}{|l|}{ Brain metastasis, n (\%) } \\
\hline Yes & $5(7.9)$ \\
\hline No & $58(92.1)$ \\
\hline \multicolumn{2}{|l|}{ Metastasis at other site, n (\%) } \\
\hline Yes & $13(20.6)$ \\
\hline No & $50(79.4)$ \\
\hline \multicolumn{2}{|l|}{ Number of metastatic sites, $\mathrm{n}(\%)$} \\
\hline 1 & $37(54.4)$ \\
\hline$\geq 2$ & $31(45.6)$ \\
\hline \multicolumn{2}{|l|}{ Previous nephrectomy, n (\%) } \\
\hline Yes & $35(55.6)$ \\
\hline No & $28(44.4)$ \\
\hline \multicolumn{2}{|l|}{ TKI regimen, $\mathrm{n}(\%)$} \\
\hline Sunitinib & $40(63.5)$ \\
\hline Pazopanib & $23(36.5)$ \\
\hline \multicolumn{2}{|l|}{ Response to TKIs, n (\%) } \\
\hline$C R$ & $3(4.8)$ \\
\hline$P R$ & $12(19.0)$ \\
\hline SD & $35(55.6)$ \\
\hline PD & $13(20.6)$ \\
\hline \multicolumn{2}{|l|}{ Neutrophil-lymphocyte ratio, n (\%) } \\
\hline$\leq 3.6$ & $34(54.0)$ \\
\hline$>3.6$ & $29(46.0)$ \\
\hline \multicolumn{2}{|l|}{ Platelet-lymphocyte ratio, n (\%) } \\
\hline$\leq 150$ & $37(58.7)$ \\
\hline$>150$ & $26(41.3)$ \\
\hline
\end{tabular}

Table 1 continued

\begin{tabular}{ll}
\hline Patient no., $\mathbf{n}$ & $\mathbf{6 3}$ \\
\hline Hemoglobin, $\mathrm{n}(\%)$ & \\
$<12(\mathrm{~g} / \mathrm{dL})$ & $25(39.7)$ \\
$\geq 12(\mathrm{~g} / \mathrm{dL})$ & $38(60.3)$ \\
Corrected calcium, $\mathrm{n}(\%)$ & \\
$<10(\mathrm{mg} / \mathrm{dL})$ & $57(90.5)$ \\
$\geq 10(\mathrm{mg} / \mathrm{dL})$ & $6(9.5)$ \\
MSKCC risk & \\
Favorable & $19(30.2)$ \\
Intermediate & $41(65.1)$ \\
Poor & $3(4.8)$ \\
Progression & $48(76.2)$ \\
Death & $29(46.0)$
\end{tabular}

IQR Interquartile range, ECOG PS Eastern cooperative oncology group performance status, $T K I$ Tyrosine kinase inhibitor, $C R$ complete response, $P R$ partial response, $S D$ stable disease, $P D$ progressive disease, MSKCC Memorial Sloan Kettering Cancer Center

The group consisted of 52 men and 11 women, with a median age of 63 [interquartile range (IQR), 56.0-70.5] years. The median follow up period was 17.5 months (IQR 9.2-28.4 months). Thirty-five (55.6\%) patients had undergone previous nephrectomy, 36 (57.1\%) patients had ECOG PS < 2, and 40 (64\%) patients had developed metastases within 1 year. Nineteen patients had bone metastases, 39 had lung metastases, 6 had liver metastases, 25 had lymph node metastases, 5 had brain metastases and 31 patients presented with multiple metastatic sites. Hemoglobin level of $<12$ was found in 25 (39.7\%) patients, corrected calcium level of $<10$ in 57 (90.5\%) patients, 48 (76.2\%) patients had tumor progression, and $29(46.0 \%)$ patients died. In addition, most patients had favorable $(n=19,30.2 \%)$ or intermediate $(n=41,65.1 \%)$ risk as determined by Memorial Sloan Kettering Cancer Center criteria (Motzer et al. 1999).

Values of NLR > 3.6 and PLR > 150 were obtained in $29(46.0 \%)$ and $26(41.3 \%)$ patients, respectively. Sunitinib was administered to 40 patients and pazopanib to 23 patients. Four types of response to TKIs were defined: complete response (CR), partial response (PR), stable disease (SD) and progressive disease (PD), which were detected in 3 (4.8\%), 12 (19.0\%), 35 (55.6\%) and 13 (20.9\%) cases, respectively. Finally, 31 patients received second line treatments using everolimus after TKI failure.

ROC curves for NLR and PLR

The areas under the ROC curves for NLR and PLR were $0.72(\mathrm{p}=0.002)$ and $0.75(\mathrm{p}=0.001)$, respectively (Fig. 1). However, the difference between the NLR and PLR values was not significant $(p=0.620)$. 


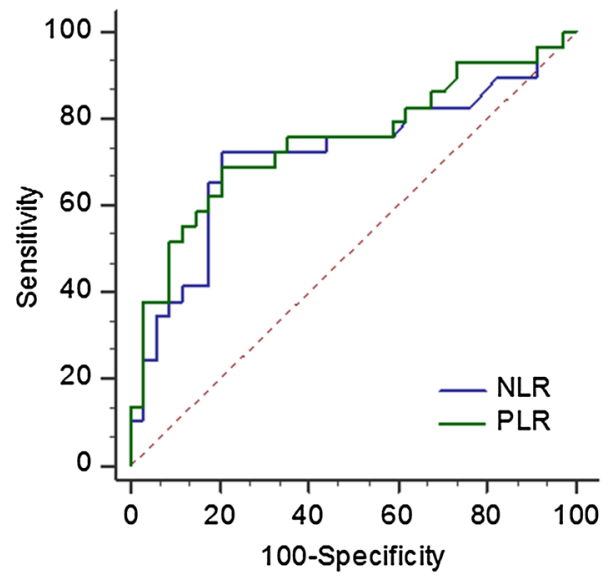

Fig. 1 Receiver operator characteristic curves for the neutrophil-lymphocyte ratio (NLR) and the platelet-lymphocyte ratio (PLR). For NLR: area under the curve $=0.72, p=0.002$, sensitivity $=72.4 \%$, specificity $=76.4 \%$, accuracy $=74.6 \%$. For PLR: area under the curve $=0.75$, $p=0.001$, sensitivity $=68.9 \%$, specificity $=79.4 \%$, accuracy $=73.0 \%$

\section{The effect of clinical variables and prognostic factors on PFS and OS}

The median PFS and OS were 10.3 months (95\% CI 8.711.9 ) and 31.9 months (95\% CI 14.2-49.5), respectively. The results of the Kaplan-Meier analysis of the effect of clinical parameters on PFS and OS are shown in Table 2. Shorter PFS was associated with an ECOG score $\geq 2$, the presence of brain metastases, $\geq 2$ metastatic sites, NLR $>3.6$ and PLR $>150$ (Table 2 , all $\mathrm{p}<0.05$ values). Multivariable analysis showed that brain metastases (HR 4.94, 95\% CI 1.75-13.9; $\mathrm{p}=0.001)$ and PLR > 150 (HR 13.1, 95\% CI 5.14-33.2; $\mathrm{p}=0.001$ ) were independent prognostic factors of PFS (Table 3 ).

Meanwhile, ECOG PS $\geq 2$, lymph node metastasis, bone metastasis, brain metastasis, number of metastatic sites $\geq 2$, NLR $>3.6$, and PLR $>150$ were related to shorter OS (Table 2, all $\mathrm{p}<0.05$ ). Also, ECOG PS $\geq 2$ (HR 3.60, 95\% CI 1.39-9.31; p = 0.008), lymph node metastasis (HR 2.76, 95\% CI 1.11-6.86; p = 0.029), brain metastasis (HR 9.39, 95\% CI 2.74-32.1; p = 0.001), and PLR > 150 (HR 16.1, 95\% CI 4.4-58.4; p = 0.001) were independent prognostic factors of OS (Table 3 ).

\section{Discussion}

Guidelines for the treatment of mRCC are rapidly evolving to incorporate the recently approved moleculartargeted therapies. Many mRCC patients have a poor prognosis, and TKIs have extremely changed their prospects. Prognostic factors can help clinicians determine the most appropriate use of TKIs by selecting the patients most likely to benefit from them (Noronha et al. 2016). Although numerous studies have attempted to determine which clinical factors might be predictors of PFS and OS, the results were inconsistent (Heng et al. 2009; Raungkaewmanee et al. 2012). In this study, we analyzed data obtained from $63 \mathrm{mRCC}$ patients receiving first-line TKI with the aim of performing prognostic evaluations and promoting optimal surveillance strategies. Many studies have proved that a poor ECOG PS remains one of the most significant prognostic factors for various malignancies, such as GI cancer, lung cancer, ovarian cancer and mRCC (Zimmermann et al. 2010). Patients with a worse ECOG PS and limited functional capacity tend to tolerate cancer treatments with more difficulty. These patients have less favorable outcomes than patients with a better PS. This has been further strengthened by similar conclusions obtained from this study. However, one of the challenges when using PS as a prognostic measure is that it is subjective and may not be reproducible (Laird et al. 2013), as it is difficult to determine it accurately in the busy clinical setting, relying heavily on patient-reported information. In 1999, the Memorial Sloan-Kettering Cancer Center (MSKCC) reported for the first time that hemoglobin level lower than the normal limit, corrected calcium level higher than the normal limit, Karnofsky performance status lower than $80 \%$ and less than 1 year interval from diagnosis to treatment were independent predictors of short survival (Motzer et al. 1999; Cetin et al. 2014). This study defined pretreatment clinical features that were prognostic of survival in previously untreated $\mathrm{mRCC}$ patients who subsequently received cytokine therapy, such as IFN- $\alpha$. Heng et al. (2009) also reported that lower hemoglobin level and higher serum corrected calcium, poor PS, and less than 1 year interval from initial diagnosis to initiation of therapy were independent predictive factors of poor survival. However, our study showed that hemoglobin and calcium levels were not significantly associated with the prognosis outcome of mRCC patients. Vickers et al. (2013) suggested that the number of brain metastases is also a prognostic factor of OS. Our study also found that the presence of brain metastases is associated with poor OS, while no significant correlation with PFS was observed. Kroeger et al. (2015) reported that the presence of lymph node metastases below the diaphragm is associated with poor survival in mRCC patients treated with targeted therapies. Our results are consistent with theirs concerning OS, but not PFS. The prognostic role of previous nephrectomy has recently been reported in patients with $\mathrm{mRCC}$ treated with target therapy (Choueiri et al. 2011; de Groot et al. 2016). Our results suggest that previous nephrectomy was not a significant prognostic factor for $\mathrm{mRCC}$ patients. All these differences may be due to the small number of analyzed $\mathrm{mRCC}$ patients and the characteristics of the study group, thus, further studies are needed. 
Table 2 Results of the Kaplan-Meier analysis of progression free and overall survival

\begin{tabular}{|c|c|c|c|c|}
\hline & $\begin{array}{l}\text { PFS, months } \\
(95 \% \mathrm{Cl})\end{array}$ & p value & $\begin{array}{l}\text { OS, months } \\
(95 \% \mathrm{Cl})\end{array}$ & $\mathrm{p}$ value \\
\hline \multicolumn{5}{|l|}{ Age } \\
\hline$<64$ years & $10.3(8.4-12.2)$ & 0.714 & $31.9(11.7-52.1)$ & 0.751 \\
\hline$\geq 64$ years & $10.4(6.7-14.1)$ & & $27.1(5.3-48.8)$ & \\
\hline \multicolumn{5}{|l|}{ Sex } \\
\hline Male & $10.6(7.5-13.6)$ & 0.245 & $31.9(12.2-51.6)$ & 0.936 \\
\hline Female & $10.1(5.8-14.2)$ & & $25.8(8.2-43.4)$ & \\
\hline \multicolumn{5}{|l|}{ ECOG PS } \\
\hline $0-1$ & $15.1(9.2-20.9)$ & 0.001 & $63.5(30.8-96.2)$ & 0.001 \\
\hline$\geq 2$ & $8.2(3.4-12.9)$ & & $15.1(10.7-19.5)$ & \\
\hline \multicolumn{5}{|c|}{ Disease free interval } \\
\hline$<1$ year & $9.2(5.1-13.3)$ & 0.063 & $22.0(0-50.5)$ & 0.131 \\
\hline$\geq 1$ year & $13.2(9.2-17.2)$ & & $41.1(16.1-65.9)$ & \\
\hline \multicolumn{5}{|c|}{ Lung metastasis } \\
\hline Yes & $6.9(2.0-11.7)$ & 0.139 & $27.1(18.4-35.7)$ & 0.722 \\
\hline No & $13.2(6.7-19.7)$ & & $37.2(12.7-61.7)$ & \\
\hline \multicolumn{5}{|c|}{ Liver metastasis } \\
\hline Yes & $4.3(0.0-11.1)$ & 0.680 & $14.4(0-49.1)$ & 0.388 \\
\hline No & $10.4(8.9-12.0)$ & & $31.9(15.8-48.0)$ & \\
\hline \multicolumn{5}{|c|}{ Lymph node metastasis } \\
\hline Yes & $10.3(7.6-13.0)$ & 0.180 & $14.4(9.1-19.7)$ & 0.037 \\
\hline No & $10.4(7.9-12.9)$ & & $40.3(28.4-52.1)$ & \\
\hline \multicolumn{5}{|c|}{ Bone metastasis } \\
\hline Yes & $10.1(6.6-13.4)$ & 0.309 & $18.2(13.3-23.1)$ & 0.021 \\
\hline No & $10.6(8.8-12.3)$ & & $40.3(20.2-60.3)$ & \\
\hline \multicolumn{5}{|c|}{ Brain metastasis } \\
\hline Yes & $3.2(2.1-4.3)$ & 0.001 & $5.9(0.1-11.7)$ & 0.012 \\
\hline No & $10.6(9.0-12.1)$ & & $37.2(17.1-57.3)$ & \\
\hline \multicolumn{5}{|c|}{ Metastasis at other site } \\
\hline Yes & $9.1(5.8-12.5)$ & 0.620 & $27.1(10.7-43.4)$ & 0.384 \\
\hline No & $10.4(8.4-12.4)$ & & $63.5(6.2-120.8)$ & \\
\hline \multicolumn{5}{|c|}{ Number of metastatic site } \\
\hline 1 & $13.2(8.7-17.7)$ & 0.001 & $40.3(24.7-55.8)$ & 0.007 \\
\hline$\geq 2$ & $5.0(0.4-9.6)$ & & $13.7(9.3-18.1)$ & \\
\hline \multicolumn{5}{|c|}{ Previous nephrectomy } \\
\hline Yes & $10.5(6.0-15.1)$ & 0.522 & $37.2(19.1-55.3)$ & 0.113 \\
\hline No & $10.3(7.1-13.5)$ & & $18.2(6.6-29.7)$ & \\
\hline \multicolumn{5}{|l|}{ TKI regimen } \\
\hline Sunitinib & $10.1(7.6-12.5)$ & 0.664 & $37.2(15.9-58.5)$ & 0.786 \\
\hline Pazopanib & $10.6(10.1-11.1)$ & & $25.8(10.2-41.3)$ & \\
\hline \multicolumn{5}{|c|}{ Neutrophil-lymphocyte ratio } \\
\hline$\leq 3.6$ & $16.3(10.4-22.2)$ & 0.001 & $63.5(37.4-89.6)$ & 0.001 \\
\hline$>3.6$ & $5.0(0.7-9.3)$ & & $17.0(12.4-21.6)$ & \\
\hline \multicolumn{5}{|c|}{ Platelet-lymphocyte ratio } \\
\hline$\leq 150$ & $18.1(6.2-29.9)$ & 0.001 & $50.5(28.5-72.4)$ & 0.001 \\
\hline$>150$ & $4.4(3.5-5.3)$ & & $13.7(7.8-19.6)$ & \\
\hline \multicolumn{5}{|l|}{ Hemoglobin } \\
\hline$<12(\mathrm{~g} / \mathrm{dL})$ & $7.2(0.3-13.9)$ & 0.237 & $25.8(8.3-43.2)$ & 0.252 \\
\hline$\geq 12(\mathrm{~g} / \mathrm{dL})$ & $11.7(8.6-14.8)$ & & $37.2(17.5-56.8)$ & \\
\hline
\end{tabular}

Table 2 continued

\begin{tabular}{|c|c|c|c|c|}
\hline & $\begin{array}{l}\text { PFS, months } \\
(95 \% \mathrm{CI})\end{array}$ & $p$ value & $\begin{array}{l}\text { OS, months } \\
(95 \% \mathrm{Cl})\end{array}$ & p value \\
\hline \multicolumn{5}{|c|}{ Corrected calcium } \\
\hline$<10(\mathrm{mg} / \mathrm{dL})$ & $10.3(8.7-11.9)$ & 0.652 & $31.9(14.4-49.4)$ & 0.206 \\
\hline$\geq 10(\mathrm{mg} / \mathrm{dL})$ & Not reached & & Not reached & \\
\hline
\end{tabular}

Table 3 Results of the multivariable analysis of variables affecting progression free and overall survival

\begin{tabular}{|c|c|c|c|c|}
\hline & \multicolumn{2}{|l|}{$\begin{array}{l}\text { Progression free } \\
\text { survival }\end{array}$} & \multicolumn{2}{|l|}{ Overall survival } \\
\hline & HR & $p$ value & HR & $p$ value \\
\hline ECOG PS $(\geq 2)$ & & & $3.60(1.39-9.31)$ & 0.008 \\
\hline $\begin{array}{l}\text { Lymph node } \\
\text { metastasis }\end{array}$ & & & $2.76(1.11-6.86)$ & 0.029 \\
\hline Brain metastasis & $4.94(1.75-13.9)$ & 0.002 & $9.39(2.74-32.1)$ & 0.001 \\
\hline $\begin{array}{l}\text { Platelet-lympho- } \\
\text { cyte ratio (>150) }\end{array}$ & $13.1(5.14-33.2)$ & 0.001 & $16.1(4.4-58.4)$ & 0.001 \\
\hline
\end{tabular}

Since Lu et al. (2006) suggested that tumors might form as a consequence of chronic inflammation, many studies have confirmed that inflammation is crucial for the development and progression of cancer. Therefore, inflammation markers have been regarded as significant for tumor progression and as risk factors for tumor recurrence. It has been recently suggested that systemic inflammationbased scores such as GPS (including albumin and CRP values), NLR, and PLR might be significant predictors of OS and PFS of cancer patients (de Vivar Chevez et al. 2014; Feng et al. 2014; Raungkaewmanee et al. 2012; $\mathrm{Hu}$ et al. 2015; Song et al. 2016; Nakano et al. 2014; Templeton et al. 2014a, b; Keskin et al. 2014). Over the last decade, it has become clear that these parameters are consistently associated with poor outcome, regardless of the tumor stage. Several studies suggested that inflammation is the key component of the tumor microenvironment, and that it has a significant role in carcinogenesis and disease progression (Balkwill and Mantovani 2012). Recent studies have tried to shed new light on molecular and cellular pathways linking inflammation and cancer (Porta et al. 2009). Despite the fact that RCC is an immunogenic tumor, there is little evidence that immune cells and inflammatory pathways can enhance the tumor's growth and immune escape. However, recent studies are beginning to uncover the mechanisms of immune escape in RCC, and the role of inflammatory immune cells and cytokines is this process (Gunduz et al. 2015; de Vivar Chevez et al. 2014). Tumor-associated neutrophils 
(TANs) have a significant role in the malignant setting, as they may act as potent antitumor effector cells. However, increasing clinical evidence shows that TANs correlate with poor prognosis. As the tumor microenvironment controls neutrophil recruitment, TANs help tumor progression (Uribe-Querol and Rosales 2015). Reduction of lymphocyte infiltration in cancer-adjacent tissues tends to lead to the proliferation and metastasis of tumor cells (Whiteside 2014). Platelets can also lead to a higher level of cancer-related coagulation (Falanga et al. 2013). It is possible that active systemic inflammation induces a poor local immune response to a tumor, leading to lymph node spread and metastasis. Therefore, the ratios of platelets, neutrophils, and lymphocytes might be important prognostic factors in various cancers. Raungkaewmanee et al. (2012) studied the predictive value of PLR and NLR on the outcome of epithelial ovarian cancer patients. They reported that higher pretreatment PLR led to shorter PFS and OS, and that PLR was a better prognostic predictor of survival than NLR. However, Chrom et al. (2016) showed that only NLR $\geq 4$ was significantly associated with shorter survival, while PLR $\geq 200$ tended to associate with poor survival. Moreover, recent study revealed that high NLR at baseline and high NLR after targeted therapy was associated with shorter PFS and OS in mRCC (Templeton et al. 2016). However, this study investigated the effect of NLR on PFS and OS without other prognostic factors. Although our study included relative small patients, we evaluated the effect of PLR on PFS and OS in $\mathrm{mRCC}$ in addition to NLR and other prognostic factors. The data obtained in this study are not entirely in accordance with available literature data. We found that ECOG PS $\geq 2$, brain metastases, multiple metastases, high NLR (>3.6), and high PLR ( $>150)$ were predictors of shorter PFS and poor OS when performing a Kaplan-Meier analysis. However, only the presence of brain metastases and a high PLR ( $>150)$ were found to be significant prognostic factors in terms of PFS and OS when performing the multivariable analysis. Our study has several limitations. First, it was a retrospective uncontrolled study regarding a single center's experience with a relatively uncommon disease, thus, the number of analyzed patients was quite small. Second, the follow-up period might not have been long enough, so a further randomized clinical study involving more mRCC patients is needed. Third, the NLR and PLR cutoff values have not been previously established and were selected from the ROC curves. Fourth, we did not assess underlying disorders and other variables (e.g., diabetes mellitus, hypertension, body mass index, smoking, diet, nutrition) of the patients. Finally, our findings were expressed in terms of PFS and OS, rather than cancer specific survival. However, an inflammationbased prognostic score is a simple, convenient, and easily determined parameter that clinicians can use for assessing the prognosis of $\mathrm{mRCC}$ patients.

\section{Conclusions}

Our results suggest that a high PLR $(>150)$ and brain metastases were associated with shorter PFS and poor OS in patients with mRCC. In addition, higher PS $(\geq 2)$ and lymph node metastases were associated with shorter OS. As PLR can be determined by readily available and inexpensive tests, it might serve as an ideal biomarker for predicting the survival of patients with $\mathrm{mRCC}$. Patients with high PLR might require a more appropriate treatment than first-line TKI such as immunotherapy using PD-1/PD-L1 inhibitors, but a larger prospective and multi-institutional study is needed in order to confirm these data.

\section{Abbreviations}

PLR: platelet-lymphocyte ratio; NLR: neutrophil-lymphocyte ratio; mRCC: metastatic renal cell cancer; TKl: tyrosine kinase inhibitors; CRP: C-reactive protein; PFS: progression-free survival; OS: overall survival; HR: hazard ratio; PS: performance status.

\section{Authors' contributions}

ECH participated in the design of the study, performed the statistical analysis and draft the manuscript. JEH participated in the design of the study and performed the statistical analysis. TJP, YHC, HSC, SHJ, JWK, SHH and YHH collected the clinical data. WKB, SIJ and DDK made critical revision of the manuscript for important intellectual content. TJP and ECH conceived of the study, and approved the final manuscript. All authors read and approved the final manuscript.

\section{Author details \\ 1 Department of Urology, Chonnam National University Medical School, 42 Jebongro, Donggu, Gwangju 501-757, Republic of Korea. ${ }^{2}$ Department of Hemato-Oncology, Chonnam National University Medical School, Gwangju, Republic of Korea. ${ }^{3}$ Department of Radiology, Chonnam National University Medical School, Gwangju, Republic of Korea. ${ }^{4}$ Department of Hepato-Pancre- ato-Biliary Surgery, Chonnam National University Medical School, Gwangju, Republic of Korea.}

\section{Acknowledgements}

None.

\section{Competing interests}

The authors declare that they have no competing interests.

\section{Ethical approval and consent to participate}

All procedures performed in studies involving human participants were in accordance with the ethical standards of the institutional research committee. The institutional ethics committee approved this study, and Informed consent was waived by the board.

Received: 25 June 2016 Accepted: 21 October 2016

Published online: 28 October 2016

\footnotetext{
References

Balkwill FR, Mantovani A (2012) Cancer-related inflammation: common themes and therapeutic opportunities. Semin Cancer Biol 22:33-40 Cetin B, Afsar B, Deger SM, Gonul II, Gumusay O, Ozet A, Benekli M, Coskun U, Buyukberber S (2014) Association between hemoglobin, calcium, and
} 
lactate dehydrogenase variability and mortality among metastatic renal cell carcinoma. Int Urol Nephrol 46:1081-1087

Choueiri TK, Xie W, Kollmannsberger C, North S, Knox JJ, Lampard JG, McDermott DF, Rini BI, Heng DY (2011) The impact of cytoreductive nephrectomy on survival of patients with metastatic renal cell carcinoma receiving vascular endothelial growth factor targeted therapy. J Urol 185:60-66

Chrom P, Stec R, Semeniuk-Wojtas A, Bodnar L, Spencer NJ, Szczylik C (2016) Fuhrman grade and neutrophil-to-lymphocyte ratio influence on survival in patients with metastatic renal cell carcinoma treated with first-line tyrosine kinase inhibitors. Clin Genitourin Cancer. doi:10.1016/j. clgc.2016.02.005

de Groot S, Redekop WK, Sleijfer S, Oosterwijk E, Bex A, Kiemeney LA, Uyl-de Groot CA (2016) Survival in patients with primary metastatic renal cell carcinoma treated with sunitinib with or without previous cytoreductive nephrectomy: results from a population-based registry. Urology. doi:10.1016/j.urology.2016.04.042

de Vivar Chevez AR, Finke J, Bukowski R (2014) The role of inflammation in kidney cancer. Adv Exp Med Biol 816:197-234

Eisenhauer EA, Therasse P, Bogaerts J, Schwartz LH, Sargent D, Ford R, Dancey J, Arbuck S, Gwyther S, Mooney M, Rubinstein L, Shankar L, Dodd L, Kaplan R, Lacombe D, Verweij J (2009) New response evaluation criteria in solid tumours: revised RECIST guideline (version 1.1). Eur J Cancer 45:228-247

Falanga A, Marchetti M, Vignoli A (2013) Coagulation and cancer: biological and clinical aspects. JThromb Haemost 11:223-233

Feng JF, Huang Y, Chen QX (2014) Preoperative platelet lymphocyte ratio (PLR) is superior to neutrophil lymphocyte ratio (NLR) as a predictive factor in patients with esophageal squamous cell carcinoma. World J Surg Oncol 12:58

Gunduz S, Mutlu H, Tural D, Yildiz Ö, Uysal M, Coskun HS, Bozcuk H (2015) Platelet to lymphocyte ratio as a new prognostic for patients with metastatic renal cell cancer. Asia Pac J Clin Oncol 11:288-292

Heng DY, Xie W, Regan MM, Warren MA, Golshayan AR, Sahi C, Eigl BJ, Ruether JD, Cheng T, North S, Venner P, Knox JJ, Chi KN, Kollmannsberger C, McDermott DF, Oh WK, Atkins MB, Bukowski RM, Rini Bl, Choueiri TK (2009) Prognostic factors for overall survival in patients with metastatic renal cell carcinoma treated with vascular endothelial growth factortargeted agents: results from a large, multicenter study. J Clin Oncol 27:5794-5799

Hu K, Lou L, Ye J, Zhang S (2015) Prognostic role of the neutrophil-lymphocyte ratio in renal cell carcinoma: a meta-analysis. BMJ Open 5:e006404

Keskin S, Keskin Z, Taskapu HH, Kalkan H, Kaynar M, Poyraz N, Toy H (2014) Prognostic value of preoperative neutrophil-to-lymphocyte and plateletto-lymphocyte ratios, and multiphasic renal tomography findings in histological subtypes of renal cell carcinoma. BMC Urol 14:95

Kroeger N, Pantuck AJ, Wells JC, Lawrence N, Broom R, Kim JJ, Srinivas S, Yim J, Bjarnason GA, Templeton A, Knox J, Bernstein E, Smoragiewicz M, Lee J, Rini BI, Vaishampayan UN, Wood LA, Beuselinck B, Donskov F, Choueiri TK, Heng DY (2015) Characterizing the impact of lymph node metastases on the survival outcome for metastatic renal cell carcinoma patients treated with targeted therapies. Eur Urol 68:506-515

Laird BJ, Kaasa S, McMillan DC, Fallon MT, Hjermstad MJ, Fayers P, Klepstad P (2013) Prognostic factors in patients with advanced cancer: a comparison of clinicopathological factors and the development of an inflammationbased prognostic system. Clin Cancer Res 19:5456-5464

Lu H, Ouyang W, Huang C (2006) Inflammation, a key event in cancer development. Mol Cancer Res 4:221-233

Motzer RJ, Mazumdar M, Bacik J, Berg W, Amsterdam A, Ferrara J (1999) Survival and prognostic stratification of 670 patients with advanced renal cell carcinoma. J Clin Oncol 17:2530-2540
Nakano K, Hosoda M, Yamamoto M, Yamashita H (2014) Prognostic significance of pre-treatment neutrophil: lymphocyte ratio in Japanese patients with breast cancer. Anticancer Res 34:3819-3824

Noronha V, Joshi A, Bakshi G, Tongaonkar H, Prabhash K (2016) Current evidence and the evolving role of sunitinib in the management of renal cell carcinoma. Indian J Cancer 53:102-108

Porta C, Larghi P, Rimoldi M, Totaro MG, Allavena P, Mantovani A, Sica A (2009) Cellular and molecular pathways linking inflammation and cancer. Immunobiology 214:761-777

Raungkaewmanee S, Tangjitgamol S, Manusirivithaya S, Srijaipracharoen S, Thavaramara T (2012) Platelet to lymphocyte ratio as a prognostic factor for epithelial ovarian cancer. J Gynecol Oncol 23:265-273

Song X, Zhang GM, Ma XC, Luo L, Li B, Chai DY, Sun LJ (2016) Comparison of preoperative neutrophil-lymphocyte, lymphocyte-monocyte, and platelet-lymphocyte ratios in patients with upper urinary tract urothelial carcinoma undergoing radical nephroureterectomy. Onco Targets Ther 9:1399-1407

Templeton AJ, McNamara MG, Šeruga B, Vera-Badillo FE, Aneja P, Ocaña A, Leibowitz-Amit R, Sonpavde G, Knox JJ, Tran B, Tannock IF, Amir E (2014a) Prognostic role of neutrophil-to-lymphocyte ratio in solid tumors: a systematic review and meta-analysis. J Natl Cancer Inst 106:dju124

Templeton AJ, Ace O, McNamara MG, Al-Mubarak M, Vera-Badillo FE, Hermanns T, Seruga B, Ocaña A, Tannock IF, Amir E (2014b) Prognostic role of platelet to lymphocyte ratio in solid tumors: a systematic review and meta-analysis. Cancer Epidemiol Biomarkers Prev 23:1204-1212

Templeton AJ, Knox JJ, Lin X, Simantov R, Xie W, Lawrence N, Broom R, Fay AP, Rini B, Donskov F, Bjarnason GA, Smoragiewicz M, Kollmannsberger C, Kanesvaran R, Alimohamed N, Hermanns T, Wells JC, Amir E, Choueiri TK, Heng DY (2016) Change in neutrophil-to-lymphocyte ratio in response to targeted therapy for metastatic renal cell carcinoma as a prognosticator and biomarker of efficacy. Eur Urol 70:358-364

Thyavihally YB, Mahantshetty U, Chamarajanagar RS, Raibhattanavar SG, Tongaonkar HB (2005) Management of renal cell carcinoma with solitary metastasis. World J Surg Oncol 3:48

Uribe-Querol E, Rosales C (2015) Neutrophils in cancer: two sides of the same coin. J Immunol Res. doi:10.1155/jir.2015.983698

Vickers MM, Al-Harbi H, Choueiri TK, Kollmannsberger C, North S, MacKenzie M, Knox JJ, Rini Bl, Heng DY (2013) Prognostic factors of survival for patients with metastatic renal cell carcinoma with brain metastases treated with targeted therapy: results from the international metastatic renal cell carcinoma database consortium. Clin Genitourin Cancer 11:311-315

Whiteside TL (2014) Tumor-infiltrating lymphocytes and their role in solid tumor progression. In: Klink M (ed) Interaction of immune and cancer cells. Springer, Vienna, pp 111-121

Zimmermann C, Burman D, Bandukwala S, Seccareccia D, Kaya E, Bryson J, Rodin G, Lo C (2010) Nurse and physician inter-rater agreement of three performance status measures in palliative care outpatients. Support Care Cancer 18:609-616

\section{Submit your manuscript to a SpringerOpen ${ }^{\circ}$ journal and benefit from:}

- Convenient online submission

- Rigorous peer review

- Immediate publication on acceptance

- Open access: articles freely available online

- High visibility within the field

- Retaining the copyright to your article

Submit your next manuscript at $\boldsymbol{\nabla}$ springeropen.com 